\title{
The Influence of Temperature on Some Fish Population Parameters in the Barents Sea
}

\author{
Harald Loeng \\ Institute of Marine Research, P. O. Box 1870 Nordnes \\ 5024 Bergen, Norway
}

\begin{abstract}
At the beginning of this century it was clear that in the Barents Sea, variations in the physical conditions have a great influence on the biological conditions of fish. The cold period during 1977-82 initiated new investigations on the influence of oceanographic conditions on recruitment, distribution and growth of commercial fish species in the Barents Sea, both by Norwegian and USSR scientists. A review of some of the most important results achieved so far is presented.

Rich year-classes of cod occur only in years with relatively high temperature on the spawning grounds and the areas of their distribution during the first half-year of their lives. Feeding distributions of cod, haddock and capelin depend on the climatic conditions in the Barents Sea with more easterly and northerly distributions noted in warm years than in cold ones. The growth of fish also seems to depend on the environmental temperature, but the temperature-growth relationships are probably not simple. The climatic fluctuations also influence the plankton production and thereby the food conditions for all plankton feeders. Temperature effects linked to the variability of food may therefore be as important as the direct effect of temperature on the biological conditions of fish.
\end{abstract}

\section{Introduction}

In a review of Norwegian cod and herring fisheries, Hjort (1914) reported fluctuations in fisheries back to the early-1700s. Some attempts had been made to explain these fluctuations, but most of the theories were valueless and only served "as indications of the state of general knowledge concerning marine biology at the periods in which they arise" (Hjort, 1914). A more scientific approach was made by Helland-Hansen and Nansen (1909) who believed that variations in the physical conditions had great influence on the biological conditions of various fish species, and that temperature variations in the sea "are the primary cause of the great and hitherto unaccountable fluctuations in the fisheries". Although Hjort (1914) was critical of this hypothesis, later investigations have shown that the physical conditions are at least important indicators for recruitment, distribution and growth of the most important commercial fish species.

During the last half of the 1970 s there was a marked temperature decrease in the whole Barents Sea, which resulted in great changes in the distribution areas of Arcto-Norwegian cod (Gadus morhua L.), haddock (Melanogrammus aeglefinus) and capelin (Mallotus villosus). This led to new investigations on the influence of climate on the biological conditions such as recruitment, distribution, migration and growth of these species, both by Norwegian and USSR scientists. The intention of this paper is to summarize and review the results from investigations carried out mainly during the 1980s. The more general ecological features of the Barents Sea was earlier reviewed by Dragesund and Gjøsaeter (1988) and Loeng (1989), while Skjoldal and Rey (1989) summarized the role of plankton production during the 1980s. Some ecological features of the adjacent Norwegian Sea were described by Blindheim (1989).

\section{Physical Conditions}

There are three main water masses in the Barents Sea. These are related to three different current systems: the Norwegian Coastal current, the Atlantic current, and the Arctic current system. Figure 1 shows the main features of these current systems. Both the Coastal and Atlantic water masses flow into the Barents Sea from the southwest and occupy the southern part of the sea. In the northern Barents Sea, the Arctic waters flow in opposite directions, towards the south and west. Between the Arctic and Atlantic waters, there is an area called the Polar front in which the two water masses mix. In the western part of the Barents Sea, the front is sharp and it separates two distinct biological regimes. In the eastern part, the front is diffused and sometimes difficult to trace.

Horizontal distribution of temperature and salinity at $100 \mathrm{~m}$ depth (Fig. 2), also shows the different water masses. According to Helland-Hansen and Nansen 


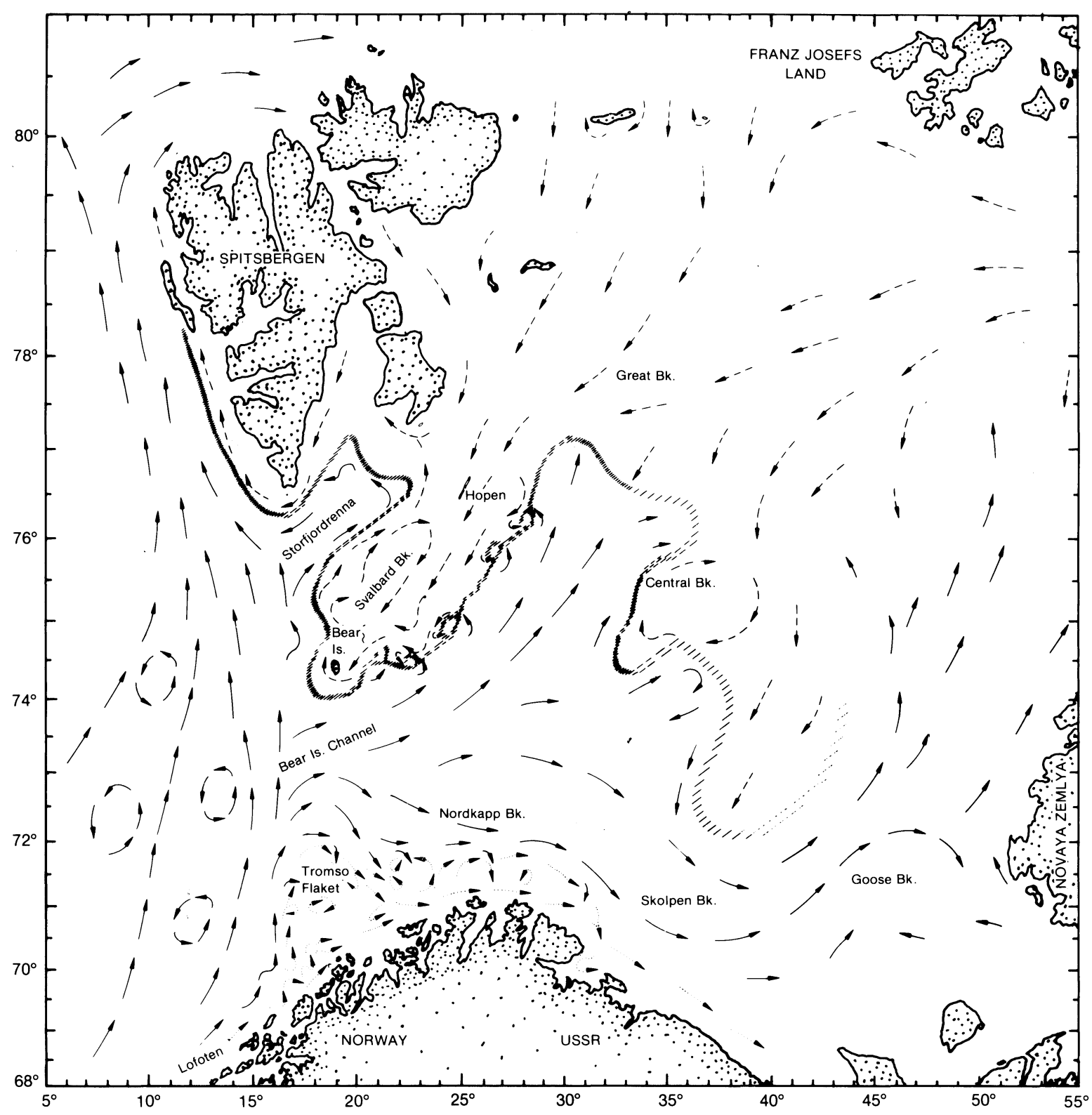

Fig. 1. Main features of surface currents in the Barents Sea. Atlantic currents $(\longrightarrow \longrightarrow$, Coastal currents $(---\rightarrow)$ and Arctic currents $(\cdots-\rightarrow \rightarrow$. The hatched line indicates the mean position of the Polar front (Loeng, 1989).
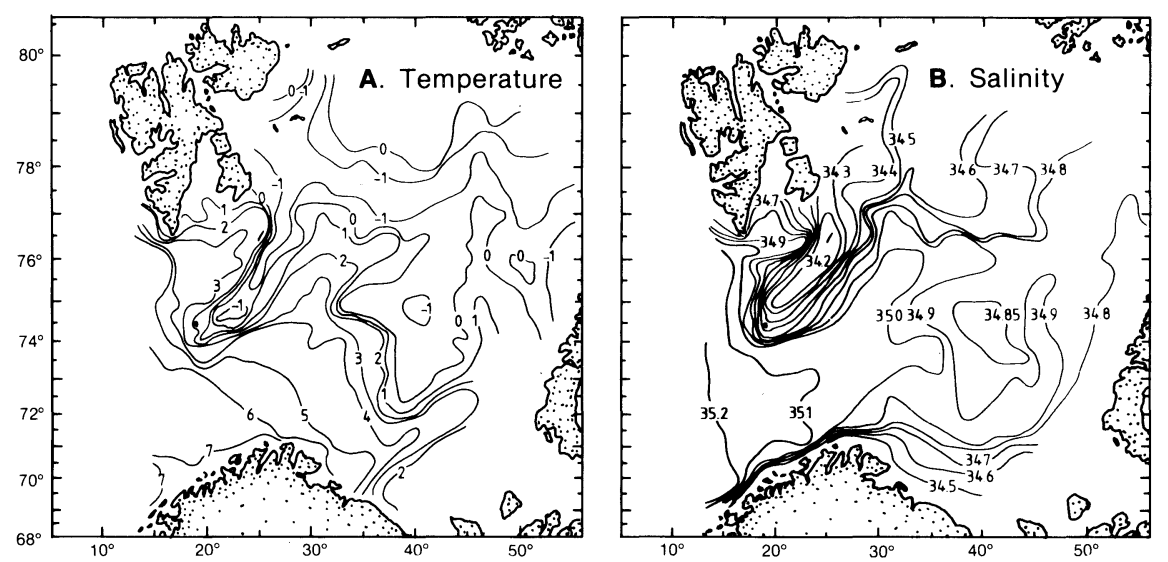

Fig. 2. Distribution of temperature (A) and salinity (B) at $100 \mathrm{~m}$ depth, during autumn 1984 (Loeng, 1989). 
(1909), the Atlantic water is defined by salinities higher than $35.0 \%$. The salinity decreases gradually eastward, and water with salinity higher than $34.9 \%$ and temperature above $2^{\circ} \mathrm{C}$ may be considered as Atlantic water. The Coastal water has almost the same temperature as the Atlantic water, but is characterized by lower salinity $(S<34.7 \%$ ). The Arctic water generally has a temperature below $0^{\circ} \mathrm{C}$, and below $-1^{\circ} \mathrm{C}$ in many areas, while the salinity varies between $34.4-34.8 \%$. In long cold periods, the eastern part of the Barents Sea may be filled with cold dense bottom water $\left(t<-1.7^{\circ} \mathrm{C}\right)$ which is formed on the bank areas off Novaya Zemlya and on the Central Bank (Midttun, 1985).

The climatic variations in the Barents Sea depend mainly on the activity and properties of the inflowing Atlantic water (Midttun and Loeng, 1987). Climatic variations therefore can be recorded in sections crossing the Atlantic current. Figure 3 shows temperature anomalies in the Kola-section after 1930 (along $33^{\circ} 30^{\prime} \mathrm{E}$ ) based on data from Bochkov (1982) and Midttun et al. (1981). Before 1940, the section was occupied irregularly, while after 1945 the observations have been carried out once a month. After a warm period in the 1930s, the years after 1945 were characterized by fluctuations of 3-5 year duration. Since 1970, large variations have been observed in the Barents Sea. The period 1970-76 was warm, while the period 1977-82 was the longest continuous cold period observed since 1920 (Loeng, 1989). During 1982 there was a strong temperature increase followed by a couple of warm years, while the subsequent years have had temperatures below the 1921-80 mean.

The same variations in temperature as in the Barents Sea were found along the whole Norwegian coast (Blindheim et al., MS 1981), indicating that these variations were large-scale. These temperature variations are as a result of advection as first suggested by Helland-Hansen and Nansen (1909), thus a time lag is indicated of about 6 months between temperature vari- ations in Lofoten, which is the spawning ground for cod, and that of the central/eastern Barents Sea (Loeng and Sundby, 1986; Ellertsen et al., 1987.)

Variations in the Atlantic inflow influence the ice conditions, especially during winter (Loeng, 1989). Loeng (1979) introduced an ice index where the ice coverage in the central Barents Sea was integrated over the year: the results are included in Fig. 3. Negative values indicate heavy ice conditions, while positive values mean there was little ice. The close relationship between the temperature of the inflowing Atlantic water and the ice conditions is apparent for the period 1970-88. The discrepancy during 1984 and 1985 was due to extremely high melting of ice during the summers, when solar radiation plays the dominant role by directly melting ice and heating the surface layer (Vinje, 1984).

\section{Recruitment of Cod}

The year-class strength of cod is mainly determined during the first year of life (Hjort, 1914). Sundby et al (1989) concluded that year-class abundance is determined during the first 6 months. There are several factors that may be responsible for the variations of the year-class strength. These include starvation at the start of exogenous feeding (Hjort, 1914; Wiborg, 1957; Kislyakov, 1961; Ellertsen et al., MS 1976, 1980 and 1984), predation on eggs and larvae (Murphy, 1961; Melle and Ellertsen, 1984) and physical factors acting directly on egg and larval populations (Garrod and Colebrook, 1978; Koslow, 1984; Sinclair et al., 1985). At the active feeding stages of larvae, variable contact rate between larvae and prey, induced by wind mixing in the surface layer, may be an important regulatory mechanism for the formation of year-class strength (Rotschild and Osborn, 1988; Sundby and Fossum, MS 1989).

Recently, relationships between temperature conditions and the year-class variations of Arcto-

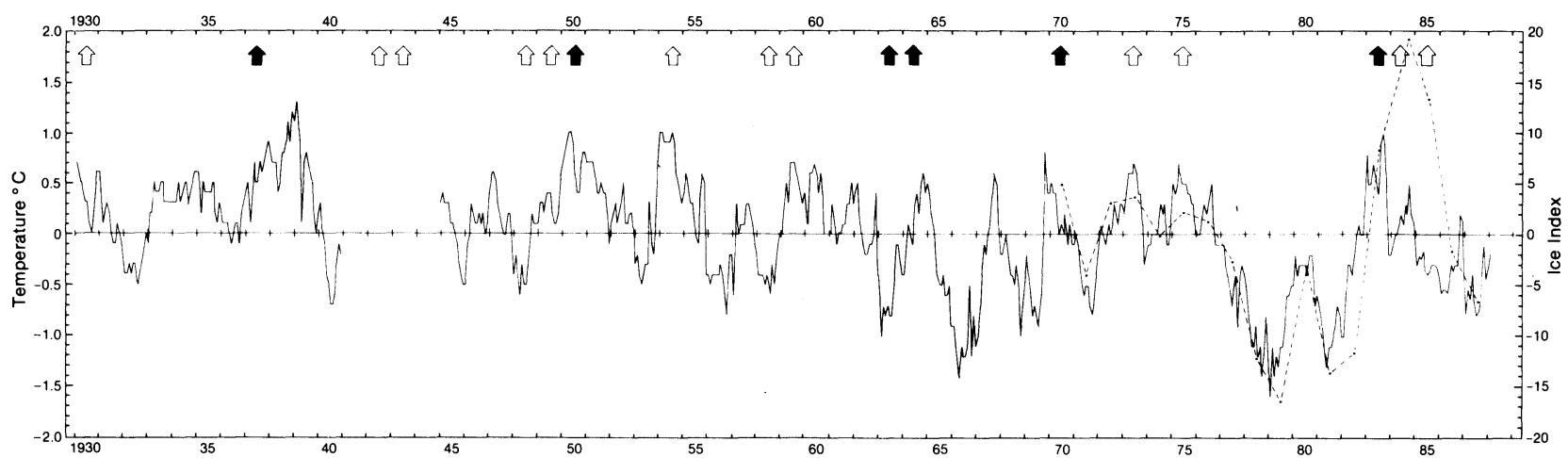

Fig. 3. Temperature anomalies in the Kola-section (along $33^{\circ} 30^{\prime} \mathrm{E}$ ) during the period $1930-88$ (solid line) together with the ice index during the period 1970-88 (dashed line). $(\Rightarrow$ indicate year-class of cod with high abundance; $\Rightarrow$ indicate year-class with medium abundance; no arrows indicate low year-class abundance) (Bochkov, 1982; Midttun et al., 1981, Saetersdal and Loeng, 1987). 
Norwegian cod have been examined. Saetersdal and Loeng (1987) concluded that the major part of the yearclasses of high and medium abundance are either associated directly with positive temperature anomalies in the early part of a warm period in the Barents Sea, when the feeding areas are expanding, or they occur immediately prior to a shift to a warmer regime, for example, 1948 and 1958 (Fig. 3). Only the year-classes 1963 and 1985 do not fit into the pattern of high recruitment with a regime of increasing temperature or positive temperature anomalies since 1930. The results for the whole period 1902-87 may be summarized as shown in Table 1. Year-classes of low abundance are most frequent, occurring in two-thirds of all years, and they are evenly distributed between cold and warm years. Year-classes of medium strength occurred twice as often in warm years as in cold ones, while year-classes of high abundance have occurred 12 times more often in warm than in cold years. If we take into account that a strong year-class on the average corresponds to two medium or ten weak year-classes (Saetersdal and Loeng, 1987), the influence of warm years on cod recruitment becomes even more important. As an example the mean yearly production during the warm period 1970-76 was 3-4 times higher than in the cold period 1977-82. Compared to the climatic variations, the years since 1970 (Fig. 3) had strong year-classes in 1970 and 1983, while the year-classes of 1973, 1975, 1984 and 1985 were of medium abundance. During the cold period 1977-82, all year-classes were of low abundance.

The effect of temperature at the spawning ground on year-class strength has been studied by Ellertsen et al. (1987). Figure 4A shows the relation between yearclass strength and the mean temperature in Lofoten (Vestfjorden) during the spawning period in MarchApril. Good year-classes never occur in cold years, while they may be produced in warm years. The "triangle plot" indicates that high temperature is a necessary, but not a sufficient condition for the production of year-classes of high abundance (Ellertsen et al., 1987). A similar "triangle plot" occurs when using temperatures from the Kola-section in August-September, which coincides with the time when the year-class appears as 0 -group fish in that area (Fig. 4B). However, there are some differences between Fig. $4 A$ and $4 B$ in that each year does not exactly have the same position along the temperature-axis. As a rule, a cold year in Lofoten corresponds to a temperature below the mean value in the Kola-section, while a warm year on the spawning ground usually is also above the mean in the

TABLE 1. Occurrence of year-classes of low, medium and high abundance in cold and warm years in the Barents Sea, 1902-87.

\begin{tabular}{lccr}
\hline & Low & Medium & High \\
\hline Cold years & $35 \%$ & $7 \%$ & $1 \%$ \\
Warm years & $31 \%$ & $14 \%$ & $12 \%$ \\
\hline
\end{tabular}

Barents Sea. An important exception was found in 1948 , when the temperature at the spawning field was high, while the temperature in the Barents Sea was slightly below the mean. Favourable conditions at the spawning ground may be an explanation for the good year-class that year.

Since the climatic variations are large-scale, one would expect that other stocks which reproduce in these ecosystems would be similarly affected. Dragesund (1971) and Saetersdal and Loeng (1987) found several years of common high recruitment in cod, haddock and herring, which gave a convincing demonstration of a close temporal relationship for larval survival. The favourable physical conditions seem to be related to increased heat transport in the Atlantic current (Saetersdal and Loeng, 1987; Mukhina et al., 1987).

\section{Distribution and Growth of Young Cod}

Immature cod feed in the Barents Sea and in the Svalbard area, and make seasonal east-west and north-
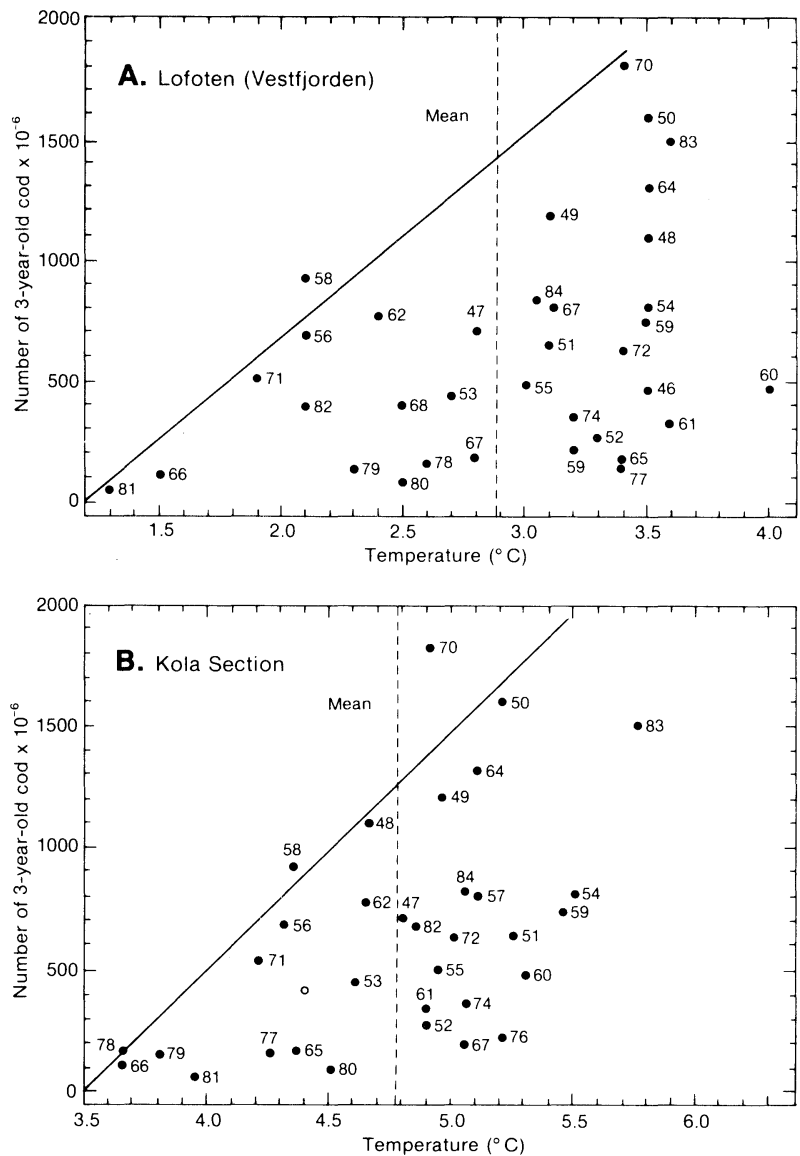

Fig. 4. The relationship between the year-class strength of cod and the mean temperature $\left({ }^{\circ} \mathrm{C}\right)$ at $(\mathbf{A})$ the spawning ground Lofoten (Vestfjorden) in March-April (Ellertsen et al., 1987) and $(\mathbf{B})$ year-class strength of cod and the mean temperature $\left({ }^{\circ} \mathrm{C}\right.$ ) at the Kola-section (along $33^{\circ} 30^{\prime} \mathrm{E}$ ) in AugustSeptember. 
south migration (Maslov, 1968; Midttun et al., 1981). In addition, there are temperature-related displacements of concentrations both on small and large time and space scales. Eggvin (1938) reported more westerly fishing areas in the Barents Sea in cold years than in warm years. Hylen et al. (1961) concluded that a connection exists between the environmental temperature and the distribution of young cod. When the temperature is high the fish are easterly distributed, while they tend to move westward with low temperatures. Konstantinov $(1967,1969)$ and Mukhin (MS 1979) came to the same conclusion on the basis of USSR trawl catches in the Barents Sea.

Since 1977, the Institute of Marine Research, Bergen, Norway, has carried out combined acoustic-trawl surveys in order to investigate the abundance and distribution of cod and haddock in the Barents Sea during early winter (Dalen et al., 1977; Hylen et al., 1986). Midttun et al. (1981) used data from these surveys to study the geographic distribution of each age-group of immature cod during a period (1977-81) with low temperatures in the whole Barents Sea (Fig. 3). Their results demonstrate a clear westward shift in the distribution of young cod year-classes in the period with decreasing temperature, causing the restriction of cod to the western half of the Barents Sea. Later, Shevelev et al. (1987) and Boytsov et al. (1987) came to the conclusion that the distributions of both immature cod and haddock were determined primarily by the heat content of the water masses. In addition, Shevelev et al. (1987) concluded that cod responds to water temperature variations faster than haddock.

The intensity of Atlantic inflow to the Barents Sea also influences the distribution of 0-group cod and haddock. The distribution is determined by the strength of the current transporting them from the spawning grounds. An easterly distribution of 0 -group of both species is probably caused by high activity of the Atlantic inflow as indicated by Randa (1984) and Mukhina et al. (1987). They used temperature as an indicator but it is most likely that a stronger Atlantic inflow does coincide with higher temperatures. Unfortunately there are no observations that relate variations on current conditions and temperature changes, however, a newly developed wind-driven numerical current model for the Barents Sea (Addlandsvik, MS 1989) showed a remarkable coincidence between volume flux of Atlantic water and temperature anomalies in the Kola-section. In warm years, the favourable feeding areas for cod larvae in the eastern Barents Sea are expanded (Ssaetersdal and Loeng, 1987), and in an early part of a warm period, there will be very few predators in that area. That should make the conditions in the eastern Barents Sea even better for 0-group cod than in the rest of the Barents Sea.
Midttun et al. (1981) also found a westward displacement of cod with increasing age. Shevelev et al. (1987) suggested that the cod year-class migrated westwards with an average of 80 nautical miles-peryear. Since the temperature decreases from west to east (Fig. 2), the younger age-groups inhabit water of lower temperatures than older ones found farther west. This is clearly shown in Fig. 5, although large year-toyear variations appear for all age-groups. On average, there appears to be a systematic increase in temperature by age of about $0.35^{\circ} \mathrm{C}$ per year for fish $>3$-yearsold (Nakken and Raknes, 1987). This indicates that these age-groups maintain their distribution within the temperature field, relative to each other, more or less independent of the absolute values of temperature during the period of observation. For fish 1- and 2-yearsold the picture is more obscure, but this may be explained by the life history of the fish prior to the first year (Nakken and Raknes, 1987). The 0-group cod descend towards bottom at the end of their first year of life, and the areas where the 1-group is observed in the beginning of the next year must, to a great extent, coincide with the areas where the fish settled (Nakken and Raknes, 1987). The location of 1-group therefore depends mainly on the drifting process of larvae in the previous year, i.e. the current conditions of the upper layer. Therefore the location of 1-year-olds within the temperature field is determined by processes which may differ from those determining the temperature conditions in the environment of the older age-groups.

Nakken and Raknes (1987) also investigated the extent to which variations in the environmental temperature of the fish influenced the growth rates. Figure 6

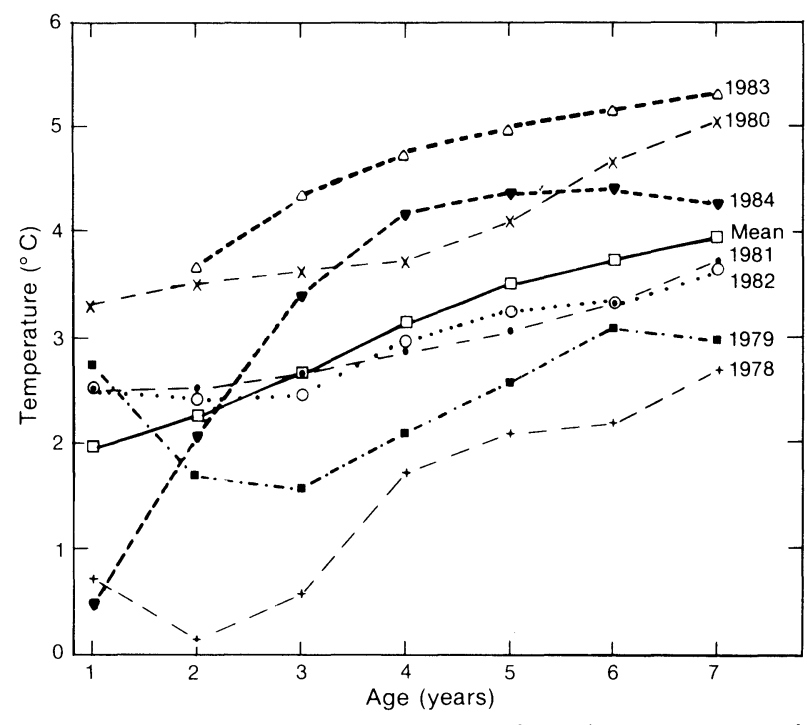

Fig. 5. Mean environmental temperatures for various age-groups of cod in February for the years 1978-84 (Nakken and Raknes, 1987). The mean temperatures for the period are indicated with a solid line. 
shows the mean length of some year-classes of cod at different ages plotted against the mean bottom temperature during winter for the last three years. Clearly, the mean length increased with increasing temperature. It may be hypothesized that the increasing growth was a consequence of decreasing stock in the considered

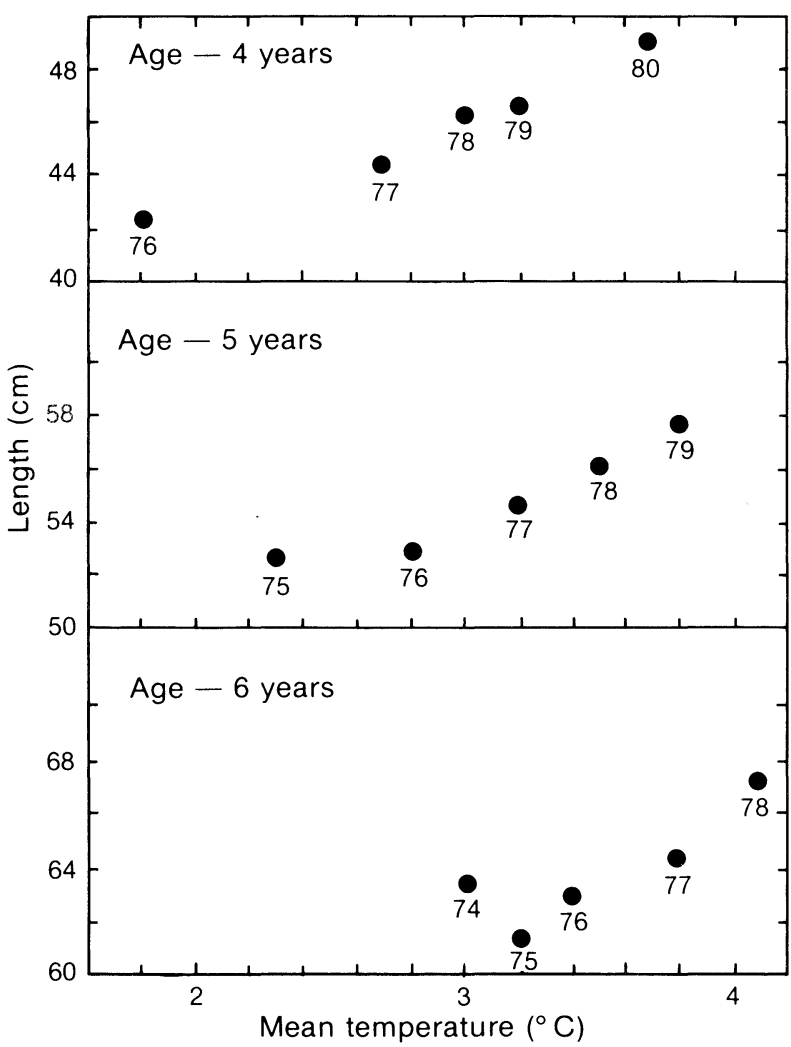

Fig. 6. Mean length of some year-classes of cod at different ages $(4,5$ and 6 years), plotted against mean environmental temperatures in February averaged over the previous 3 years (Nakken and Raknes, 1987). period, but since the cod stock amounted to only a fraction of its normal level (about 20\%), Nakken and Raknes (1987) discounted that possibility. They concluded that the increased growth was due to the increased environmental temperature.

Another example indicating temperature dependent growth is shown in Fig. 7. This shows the length distribution of cod 3 years of age in the Barents Sea during winter 1984 . The length decreases from west to east in the same way as the temperature (Fig. 2). The same result is also valid for other age-groups and in different years.

The increased growth indicated in Fig. 6, might have led to maturation of the cod at a younger age than in previous years. Hylen and Nakken (MS 1982, MS 1983, MS 1984) have shown that the percentage of younger fish in the spawning stock increased significantly during the early-1980s. The year-classes for which earlier maturation has occurred have inhabited progressively warmer waters and have consistently shown increasing growth and decreasing abundance (Nakken and Raknes, 1987).

\section{Distribution and Growth of Capelin}

The large temperature fluctuations which have occurred since the mid-1970s have had great effect both on the spawning and feeding migrations and on the distribution of spawning, feeding and overwintering of capelin. Changes in the environmental temperature have also influenced their growth rate.

During summer and autumn, the adult stock of capelin feed in the northern part of the Barents Sea (Fig. 8). They are found in both Atlantic and Arctic

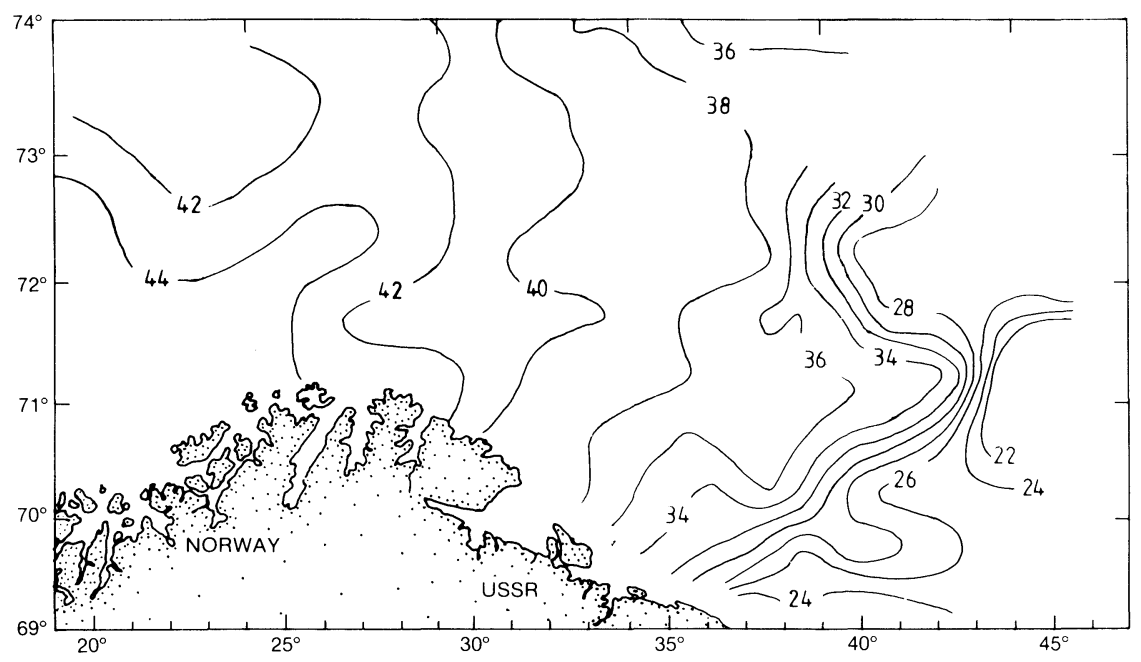

Fig. 7. Distribution of the different length groups (in $\mathrm{cm}$ ) of 3-year-old cod in February 1984 

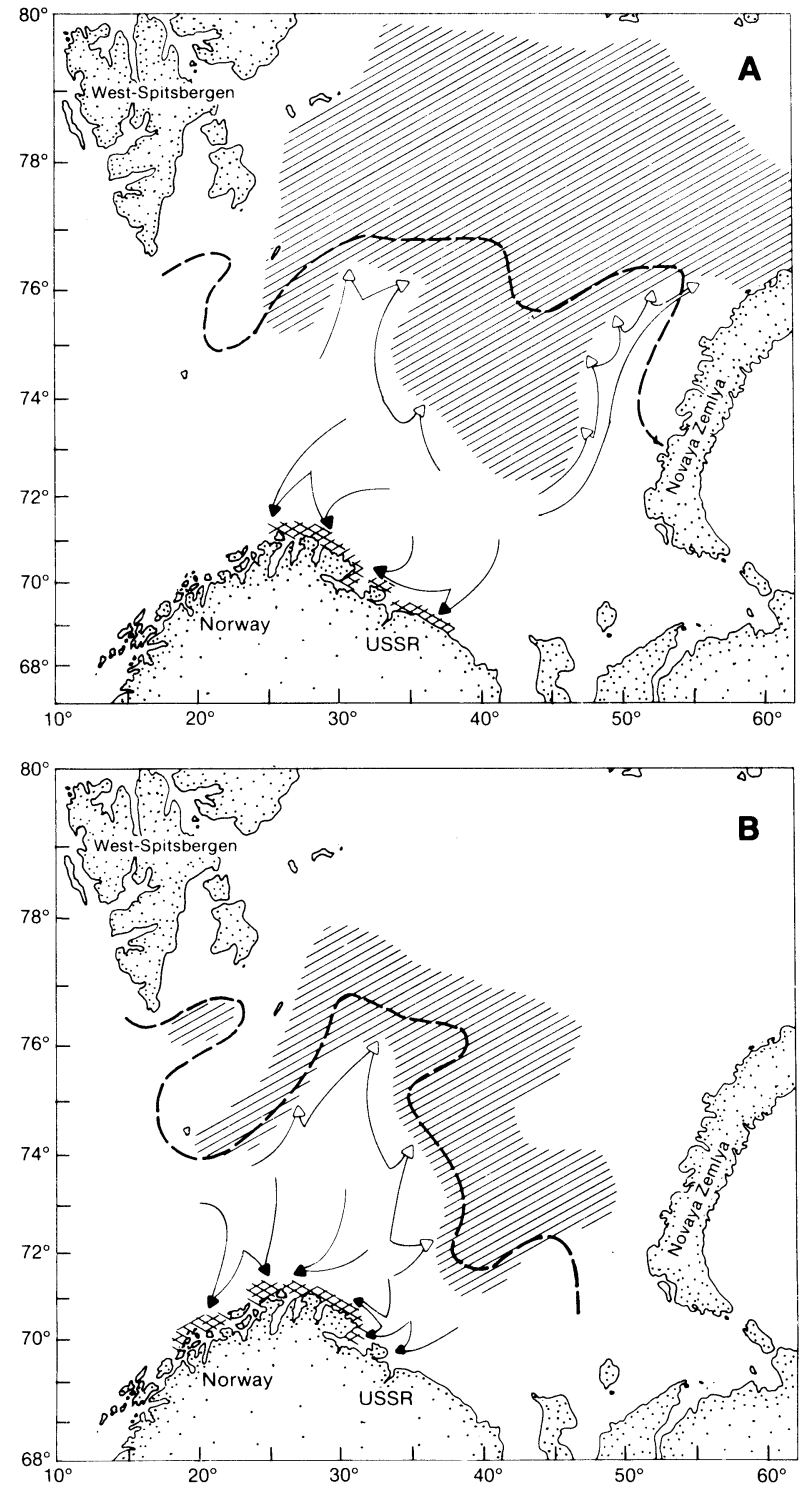

Fig. 8. Feeding distribution (hatched) and spawning ground (double hatched) of capelin in (A) warm years and (B) in cold years. $(\longrightarrow$ indicate feeding migration; $\longrightarrow$ indicate spawning migration routes. The dashed line indicates the approximate position of the $0^{\circ} \mathrm{C}$-isotherm at $100 \mathrm{~m}$ in warm and cold years (Loeng, 1981; Loeng et al., 1983; Ozhigin and Luka, 1985).

waters, and the majority of adults seem to stay in water masses with mean temperatures between $-1^{\circ}$ and $+2^{\circ} \mathrm{C}$ (Loeng, 1989). Large-scale changes of water temperature seem to generate a significant displacement of their distribution as indicated in Fig. 8 (Loeng, 1981, Loeng et al., 1983; Ozhigin and Luka, 1985). During warm periods, as in the first half of the 1970s (Fig. 3), they were found to reach the extremity of their distribution area at close to $80^{\circ} \mathrm{N}$ and along the northern coast of Novaya Zemlya. In cold years, such as the period 1977-81, capelin had a more southwesterly distribution.
TABLE 2. Mean temperature $\left({ }^{\circ} \mathrm{C}\right)$ in the distribution area of 2-, 3- and 4-year-old capelin, 1974-85 (Gjøsaeter and Loeng, 1987).

\begin{tabular}{lrrr}
\hline & \multicolumn{3}{c}{ Age } \\
\cline { 2 - 4 } Year & \multicolumn{1}{c}{3} & \multicolumn{1}{c}{3} & \multicolumn{1}{c}{4} \\
\hline 1974 & -1.15 & -0.18 & 0.32 \\
1975 & -0.03 & -0.29 & -0.26 \\
1976 & 0.16 & 0.46 & 0.76 \\
1977 & -0.32 & -0.38 & -0.37 \\
1978 & 0.03 & -0.11 & 0.13 \\
1979 & -0.05 & -0.19 & -0.05 \\
1980 & 0.78 & 0.68 & 0.85 \\
1981 & 0.63 & 0.53 & 0.53 \\
1982 & 1.12 & 0.99 & 1.13 \\
1983 & 1.82 & 1.95 & 2.11 \\
1984 & 0.56 & 0.99 & 1.04 \\
1985 & 0.29 & 0.55 & 0.61 \\
\hline
\end{tabular}

During the relatively slow temperature decrease from 1976 to 1979, the capelin responded to the cooling by a southward and westward movement (Loeng, 1981). During this period, the mean concentrations of 2-4 year-olds were found in a constant position relative to the temperature field (Table 2). In 1980 and 1981 there was a change in distribution relative to the environmental temperature and during the period of rapid warming in 1982-83, no corresponding movement of the distribution area took place as the environmental temperature consequently increased to a maximum in 1983 (Table 2). Later there was a small northeastward movement in geographical distribution at the same time as a small temperature decrease occurred in the area. The environmental temperature in these most recent years have in fact approached the same level as those in the 1970s indicating that capelin does not immediately respond to rapid thermal changes. According to Ushakov and Ozhigin (1987) there is a 1-2 year delay in response to climatic influences.

Large-scale temperature variations also cause changes in the location of the spawning grounds and the spawning migration routes. According to Ushakov and Ozhigin (1987), temperatures of $2^{\circ}$ to $3^{\circ} \mathrm{C}$ are optimal for spawning. Therefore, in cold years, the main spawning grounds are found along the coast of northern Norway, while in warm years there is more easterly spawning (Fig. 8).

Gjøsaeter and Loeng (1987) analyzed growth of capelin in relation to temperature. They found a close within-year relationship between the two variates, and that growth increased by approximately $0.3 \mathrm{~cm}$ per ${ }^{\circ} \mathrm{C}$. However, in different years, a given temperature was associated with different levels of growth, as shown in Fig. 9 while growth differences from year to year cannot be directly assigned to temperature variations.

Gjøsaeter and Loeng (1987) also found a relationship between feeding area and growth. The growth in the southern and western parts was generally higher 


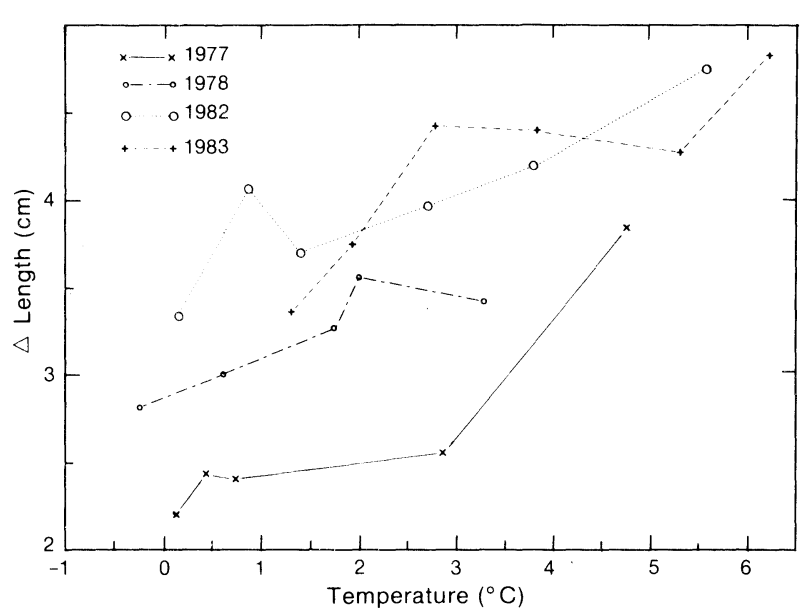

Fig. 9. Increase in length plotted against temperature for 2-year-old capelin in different areas of the Barents Sea in the years 1977 , 1978, 1982 and 1983 (Gjøsaeter and Loeng, 1987).

than in the northern areas. This relationship seemed to be a function of temperature and may be more useful as a management tool than the direct relationship between temperature and growth. In periods of approximately stable fish stocks and feeding conditions, there seems to be a relationship between the climate and the distribution of capelin. Knowing the large-scale development of the sea climate, a valid forecast of the feeding area for the next year may be given (Ozhigin and Ushakov, 1985), and thus also a rough estimate of the expected growth (Gjøsaeter and Loeng, 1987).

\section{Discussion}

In growth studies of cod, Nakken and Raknes (1987) concluded that the coupling between environmental changes and population parameters, such as areas of distribution, abundance, growth and maturity, was probably far more complex than a simple lengthtemperature relationship. Gjøsaeter and Loeng (1987) came to the same conclusion when they studied the growth of capelin. It is apparent that temperature effects linked to the availability of food may be as important as these direct effects. Various mechanisms are conceivable. A shift in climate could alter the general physical conditions, thus altering the availability of nutrients for the primary producers. It could also affect the growth of organisms at different levels in the food web and influence the abundance of food competitors, predators and so on.

Variations in the Atlantic inflow determine the water temperature in the southern Barents Sea, the position of the polar front and the ice conditions (Loeng, 1989). These will in turn affect the local planktonic primary and secondary production, which provides the food base that supports the large commercial fish resources. In addition, the advective transport of zooplankton by currents is known to vary with the rate of Atlantic inflow (Ozhigin and Ushakov, 1985). Consequently, the current system wili influence the growth of plankton feeders through variations in available food. This may partly explain the difference in growth for equal temperature from one year to another, as observed for capelin by Gjøsaeter and Loeng (1987). In that case, the water temperature was not the primary cause of change of food availability, but was only an indicator of change in the water masses. Unfortunately there are still no information on how changes in zooplankton biomass influence capelin growth. Calculations made by Skjoldal and Rey (1989) suggested that the capelin stock in the late-1970s was nearly as high as the plankton production in the feeding area could sustain. This suggested that the growth of capelin may also be density dependent.

Temperature variations have a pronounced effect on the timing of the spring bloom in the Barents Sea, mediated mainly through the effect of the stable formation of the pycnocline. In the polar front area and in the Atlantic water just south of the frontal area, the spring phytoplankton bloom starts earlier in cold years and culminates a month or more prior to the bloom in warm years (Rey et al., 1987; Skjoldal et al., 1987). Both papers also concluded that in warm years the primary production from the spring bloom available for zooplankton would be larger than in cold years and most of it would be channelled to the pelagic ecosystem. In cold years the zooplankton spawning starts later than in warm ones (Degtereva, 1979). Therefore the copepodite stages of zooplankton do not reach a size which allows them to fully utilize the early phytoplankton bloom (Skjoldal et al., 1987). This will of course result in less food for all plankton feeders. In contrast, the slower bloom development in warmer years may be more favourable for copepodite development. It may therefore be concluded that the pelagic food web will benefit from years with high Atlantic inflow.

The feeding conditions for fish larvae may also influence the year-class strength. Temperature affects the timing of spawning of copepods, and the development of copepod eggs and larvae is also directly affected by temperature (Ellertsen et al., 1987). The temperature dependent spawning of the copepod Calanus finmarchicus found in Lofoten, which caused a delay in spawning by about 1.5 months in the coldest and the warmest years, 1981 and 1960 respectively (Fig.4A), may be the most important process to cause variability in cod larval survival (Ellertsen et al., 1989). There are also temperature dependent processes related to recruitment. Rapid development through the egg and larval stages would decrease mortality by predation and reduce transport and dispersion out of favourable first feeding areas (Ellertsen et al., 1989). Therefore, high water temperatures may only be an indicator and not a direct cause of a strong year-class. 
If an adult fish experiences a temperature near the boundaries of its tolerance,range, it could in most cases move actively away from such areas. Thus, it is plausible that the temperature conditions affect the northern and eastern boundaries of fish distribution in the Barents Sea. Temperature observations may therefore be used to forecast the outermost limits of distribution for the different fish species.

\section{Acknowledgements}

I thank Karen Gjertsen and Ingrid Byrkjedal for heip with preparing the manuscript. This work has been partly supported by the Norwegian Fisheries Research Council (NFFR).

\section{References}

ÅLANDSVIK, B. MS 1989. Wind-driven variations in the Atlantic inflow to the Barents Sea. ICES C.M. Doc., No. C:18, $13 \mathrm{p}$.

BLINDHEIM, J. 1989. Ecological features of the Norwegian Sea. In: Proceedings of the sixth Conference of Comite Arctique International: 13-15 May 1985, L. Rey and V. Alexander (eds.), p. 366-401. E. J. Brill.

BLINDHEIM, J., H. LOENG, and R. SAETRE. MS 1981. Longterm temperature trends in Norwegian coastal waters. ICES C.M. Doc., No. C:19, 13 p.

BOCHKOV, Yu. A. 1982. Water temperature in the $0-200 \mathrm{~m}$ layer on the Kola-Meridian in the Barents Sea, 1900-1981. Sb. Nauchn. Trud. PINRO, Murmansk, 46: 113-122 (in Russian).

BOYTSOV, V. D., A. I. MUKHIN, and N. A. YARAGINA. 1987. Peculiarities of feeding migration of the Lofoten-Barents Sea in relation to variability of environmental conditions. In: The effect of oceanographic conditions on distribution and population dynamics of commercial fish stocks in the Barents Sea, H. Loeng (ed.). Proceedings of the third Soviet-Norwegian Symposium, Murmansk, 26-28 May 1986. Inst. of Mar. Res., Bergen, Norway, p. 191-197.

DALEN, J., L. MIDTTUN, C. J. R $\varnothing$ RVIK, and O. M. SMEDSTAD. 1977. Demersal fish investigations in the Barents Sea in winter 1977. Fisken Havet, 1977(2): 17-33 (in Norwegian with English abstract).

DEGTEREVA, A. A. 1979. Regularities of quantitative development of zooplankton in the Barents Sea. Trudy PINRO, Murmansk, 43: 22-53 (in Russian).

DRAGESUND, O. 1971. Comparative analysis of year-class strength among fish stocks in the North Atlantic. Fiskeridir. Skr. (Havunders.), 16: 49-64.

DRAGESUND, O., and J. GJ ØSAETER. 1988. The Barents Sea. In: Ecosystems of the world, H. Postma and J. J. Zijlstra (eds.). Continental Shelves, p. 339-361. Elsevier.

EGGVIN, J. 1938. Trekk fra Nord-Norges oceanografi sett $i$ sammenheng med torskefisket. Fiskeridir. Skr. (Havunders.), 5: 33-46 (in Norwegian).

ELLERTSEN, B., P. FOSSUM, P. SOLEMDAL, and S. SUNDBY. 1989. Relation between temperature and survival of eggs and first-feeding larvae of Northeast Arctic cod (Gadus morhua L.). ICES Rapp. Proc.-Verb., 191: 209-219.
ELLERTSEN, B., P. FOSSUM, P. SOLEMDAL, S. SUNDBY, and S. TILSETH. 1984. A case study on the distribution of cod larvae and availability of prey organisms in relation to physical processes in Lofoten. In: The propagation of cod Gadus morhua L., Flødevigen rapportser., 1, E. Dahl, D. S. Danielssen, E. Moksness, and P. Solemdal (eds.), p. 453-477.

1987. The effect of biological and physical factors on the survival of Arcto-Norwegian cod and the influence on recruitment variability. In: The effect of oceanographic conditions on distribution and population dynamics of commercial fish stocks in the Barents Sea, H. Loeng (ed.). Proceedings of the third Soviet-Norwegian Symposium, Murmansk 26-28 May 1986. Inst. of Mar. Res., Bergen, Norway, p. 101-126.

ELLERTSEN, B., E. MOKSNESS, P. SOLEMDAL, T. STR ØMME, S. TILSETH, and V. ØIESTAD. MS 1976. The influence of light and food density on the feeding success in larvae of cod (Gadus morhua L.); field and laboratory observations. ICES C.M. Doc., No. F:34, 16 p.

ELLERTSEN, B., E. MOKSNESS, P. SOLEMDAL, T. STR $\varnothing M M E, S$. TILSETH, T. WESTGARD, and V. ØIESTAD. 1980. Some biological aspects of cod larvae (Gadus morhua L.). Fiskeridir. Skr. (Havunders.), 17: 29-47.

GARROD, D. J., and J. M. COLEBROOK. 1978. Biological effects of variability in the North Atlantic ocean. ICES Rapp. Proc.-Verb., 173: 128-144.

GJ $\varnothing$ SAETER, H., and H. LOENG. 1987. Growth of the Barents Sea capelin, Mallotus villosus, in relation to climate. Environmental Biology of Fishes 20(4): 293-300.

HELLAND-HANSEN, B., and F. NANSEN. 1909. The Norwegian Sea. Fiskeridir. Skr. (Havunders.), 2: 1-360.

HJORT, J. 1914. Fluctuations in the great fisheries of northern Europe viewed in the light of biological research. ICES Rapp. Proc.-Verb., 20: 1-228.

HYLEN, A., and O. NAKKEN. MS 1982. Stock size of Northeast Arctic cod, estimated from acoustic survey data 1982. ICES C.M. Doc., No. G: 61, 12 p.

MS 1983. Stock size of Northeast Arctic cod, estimated from acoustic survey data 1982/83. ICES C.M. Doc., No. G:57, 14 p.

MS 1984. Stock size of Northeast Arctic cod, estimated from acoustic survey data 1983/84. ICES C.M. Doc., No. G:45, 13 p.

HYLEN, A., L. MIDTTUN, and G. SAETERSDAL. 1961. Torskeunders $\varnothing$ kelsene i Lofoten og Barentshavet 1960. Fiskets. Gang, 47: 101-114 (in Norwegian).

HYLEN, A., O. NAKKEN, and K. SUNNANA. 1986. The use of acoustic- and bottom trawl surveys in the assessment of the Northeast Arctic cod and haddock stocks. In: Proceedings of a workshop on comparative biology, assessment and management of gadoids from the North Pacific and Atlantic Oceans, M. Alton (ed.). Seattle, Washington, June, 1985.

KISLYAKOV, A. G. 1961. The relation of hydrological conditions to fluctuations in the abundance of cod yearclasses. Trans. Ichthyol. Comm. Acad. Sci., USSR, 13: 260-264.

KONSTANTINOV, K. G. 1967. Forecasting of the distribution of fish concentrations in the Barents Sea according to the temperature factor. Fish. Res. Board Can. Transl. Ser., No. $1132,28 \mathrm{p}$.

1969. Effect of natural factors and fishing on the abundance of groundfish in northern seas. Fish. Res. 
Board Can. Transl. Ser., No. 1559, 12 p.

KOSLOW, A. 1984. Recruitment patterns of Northwest Atlantic fish stocks. Can. J. Fish. Aquat. Sci., 41: 1722-1729.

LOENG, H. 1979. A review of the sea ice conditions of the Barents Sea and the area west of Spitsbergen. Fisken Havet, 1979(2): 29-75 (in Norwegian with English abstract).

1981. On the northerly distribution of capelin and temperature conditions in the Barents Sea in autumn. Fisken Havet. 1981(1): 1-10 (in Norwegian with Englsih abstract).

1989. Ecological features of the Barents Sea. In: Proceedings of the sixth Conference of Comite Arctique International: 13-15 May 1985, L. Rey and V. Alexander (eds.), p. 327-365, E. J. Brill.

LOENG, H., and S. SUNDBY. 1986. Hydrography and climatology of the Barents Sea and the coastal waters of northern Norway. In: Proceedings of workshop on comparative biology, assessment, and management of gadoids from the North Pacific and Atlantic Oceans, M. Alton (ed.), Seattle, Washington, June 1985.

LOENG, H., O. NAKKEN, and A. RAKNES. 1983. The distribution of capelin in the Barents Sea in relation to the water temperature in the period 1974-1982. Fisken Havet, 1983(1): 1-17 (in Norwegian with English abstract).

MASLOV, N. A. 1968. The influence of natural factors and fishing upon the age composition, abundance and distribution of the Barents Sea bottom fishes. Proceedings of the Polar Research Institute of Marine Fisheries and Oceanography (PINRO), Murmansk, 23: 86-103. (Canadian translation, 1975.)

MELLE, W., and B. ELLERTSEN. 1984. Predation on cod eggs and larvae; potential predators in the spawning ground of the Northeast Arctic cod. ICES Larval Fish Ecology WG, Hirtshals, Denmark, 25-27 June: 1-19.

MIDTTUN, L. 1985. Formation of dense bottom water in the Barents Sea. Deep-Sea Res., 32(10): 1233-1241.

MIDTTUN, L., and H. LOENG. 1987. Climatic variations in the Barents Sea. In: The effect of oceanographic conditions on distribution and population dynamics of commercial fish stocks in the Barents Sea, H. Loeng (ed.). Proceeding of the third Soviet-Norwegian Symposium, Murmansk, 26-28 May 1986. Inst. of Mar. Res., Bergen, Norway, p. $13-27$.

MIDTTUN, L., O. NAKKEN, and A. RAKNES. 1981. Variations in the geographical distribution of cod in the Barents Sea in the period 1977-1981. Fisken Havet, 1981(4): 1-16 (in Norwegian with English abstract).

MUKHIN, A. I. MS 1979. Distribution of the demersal fishes in the southern Barents Sea depending on the heat content of water masses. ICES C.M. Doc., No. G:18, 8 p.

MUKHINA, N. V., A. I. MUKHIN, and E. A. DVININA. 1987. Oceanographic conditions and reproduction of ArctoNorwegian cod of the Barents Sea in 1980-1985. In: The effect of commercial conditions on distribution and population dynamics of commercial fish stocks in the Barents Sea, H. Loeng (ed.). Proceedings of the third SovietNorwegian Symposium, Murmansk 26-28 May 1986. Inst. of Mar. Res., Bergen, Norway, p. 145-158.

MURPHY, G. I. 1961. Oceanography and variation in the Pacific sardine populations. Rep. Calif. Ocean. Fish. Invest., 8: 54-64.

NAKKEN, O., and A. RAKNES. 1987. The distribution and growth of Northeast Arctic cod in relation to bottom temperatures in the Barents Sea, 1978-1984. Fish. Res., 5 243-252.
OZHIGIN, V. K., and G. I. LUKA. 1985. Some peculiarities of capelin migrations depending on thermal conditions in the Barents Sea. In: Proceedings of the Soviet-Norwegian symposium on the Barents Sea capelin, H. Gjфsaeter (ed.). Inst. of Mar. Res., Bergen, Norway, p. 135-147.

OZHIGIN, V. K., and N. G. USHAKOV. 1985. The effect of the thermal conditions of the sea and atmospheric circulation on the distribution of the Barents Sea capelin feeding areas. In: Proceedings of the Soviet-Norwegian Symposium on the Barents Sea capelin, H. Gjøsaeter (ed.). Inst. of Mar. Res., Bergen, Norway, p. 149-156.

RANDA, K. 1984. Abundance and distribution of 0-group Arcto-Norwegian cod and haddock 1965-1982. In: Proceedings of the Soviet-Norwegian Symp: Reproduction and recruitment of Arctic cod, R. O. God $\varnothing$ and S. Tilseth (eds.). Inst. of Mar. Res., Bergen, Norway, p. 192-212.

REY, F., H. R. SKJOLDAL, and D. SLAGSTAD. 1987. Primary production in relation to climatic changes in the Barents Sea. In: The effect of oceanographic conditions on distribution and population dynamics of commercial fish stocks in the Barents Sea, H. Loeng (ed.). Proceedings of the third Soviet-Norwegian Symposium, Murmansk, 26-28 May 1986. Inst. of Mar. Res., Bergen, Norway p. 29-46.

ROTSCHILD, B. J., and T. R. OSBORN. 1988. Small-scale turbulence and plankton contact rates. J. Plank. Res., 10(3): $465-474$.

SAETERSDAL, G., and H. LOENG. 1987. Ecological adaption of reproduction in Northeast Arctic cod. Fish. Res., 5: 253-270.

SHEVELEV, M. S., V. V. TERESCHENKO, and N. A. YARAGINA. 1987. Distribution and behaviour of demersal fishes in the Barents and Norwegian Seas, and the factors influencing them. In: The effect of oceanographic conditions on distribution and population dynamics of commercial fish stocks in the Barents Sea, H. Loeng (ed.). Proceedings of the third Soviet-Norwegian symposium, Murmansk, 26-28 May 1986. Inst. of Mar.Res., Bergen, Norway, p. 181-190.

SINCLAIR, M., M. J. TREMBLAY, and P. BERNAL. 1985. EI nino events and variability in a Pacific mackerel (Scomber japonicus) survival index: support for Hjort's second hypothesis. Can. J. Fish. Aquat. Sci., 42: 602-608.

SKJOLDAL, H. R., and F. REY. 1989. Pelagic production and variability of the Barents Sea ecosystem. In: Biomass yields and geography of large marine ecosystems, $\mathrm{K}$. Sherman and L. M. Alexander (eds.). American Association for the Advancement of Science, p. 241-286.

SKJOLDAL, H. R., A. HASSEL, F. REY, and H. LOENG. 1987. Spring phytoplankton development and zooplankton reproduction in the central Barents Sea in the period 1979-1984. In: The effect of oceanographic conditions on distribution and population dynamics of commercial fish stocks in the Barents Sea, H. Loeng (ed.). Proceedings of the third Soviet-Norwegian symposium, Murmansk, 26-28 May 1986. Inst. of Mar. Res., Bergen, Norway p. $59-89$.

SUNDBY, S., H. BJ ØRKE, A. V. SOLDAL, and S. OLSEN. 1989. Mortality rates during the early life stages and year-class strength of Northeast Arctic cod (Gadus morhua L.). ICES Rapp. Proc.-Verb., 191: 351-358.

SUNDBY, S., and P. FOSSUM. MS 1989. Feeding conditions of Northeast Arctic (Arcto-Norwegian) cod larvae compared to the Rotschild-Osborn theory on small-scale turbulence and plankton contact rates. ICES C.M. Doc., No. G: 19, $11 \mathrm{p}$. 
USHAKOV, N. G., and V.K. OZHIGIN. 1987. The abundance of year-classes of the Barents Sea capelin and peculiarities of the distribution of the young in relation to hydrographic conditions. In: The effect of oceanographic conditions on distribution and population dynamics of commercial fish stocks in the Barents Sea, H. Loeng (ed.). Proceedings of the third Soviet-Norwegian symposium, Murmansk, 26-28 May 1986. Inst. of Mar. Res., Bergen, Norway, p. 159-167.

VINJE, T. E. 1984. Frequency distribution of sea ice, ridges and water openings in the Greenland and Barents Seas A preliminary report on the "Birds Eye" observations. Norsk. Polarinst. Rapporster., 15: 1-27.

WIBORG, K. F. 1957. Factors influencing the size of the yearclasses in the Arcto-Norwegian tribe of cod. Fiskeridir. Skr. (Havunders.), 11(8): 1-24. 
